\title{
Empreendedorismo
}

criativo: as diretrizes do

\section{setor de design de moda}

em Lisboa pela

percepção de produtores

criativos

Maria Débora Fernandes Pontes

Doutoranda, Universidade Federal de Pernambuco/ deborapnts@hotmail.com

Orcid: 0000-0003-1289-2598 / lattes

Maria Alice Vasconcelos Rocha

Doutora, Universidade Federal Rural de Pernambuco / modalice.br@gmail.com

Orcid: 0000-0001-8515-2668 / lattes

Hans da Nóbrega Waechter

Doutor, Universidade Federal de Pernambuco / hnwaechter@gmail.com

Orcid: 0000-0001-5222-6093 / lattes

Enviado: 11/12/2020 // Aceito: 19/05/2021 


\title{
Empreendedorismo criativo: as diretrizes do setor de design de moda em Lisboa pela percepção de produtores criativos
}

\begin{abstract}
RESUMO
O estudo apresentado tem por objetivo levantar questões quanto a percepção de produtores criativos e de sua capacidade em participar e se adaptar ao modelo de economia emergente, pautada no desenvolvimento de criatividade e processos autorais de criação de produtos. Para tanto, levouse em consideração as transformações observadas ao longo da última década, e que apresentaram Lisboa com uma cidade com potencial para tornar-se expoente em inovação e empreendedorismo criativo. A partir de levantamentos documentais de índices econômicos recentes e identificação de iniciativas, marcas e produtores autorais, foram verificados alguns dos fatores que favoreceram o desenvolvimento do setor. Os dados que compõem a pesquisa foram fundamentados em entrevistas com designers empreendedores, cujos discursos forneceram material para posterior análise. A análise da perspectiva dos profissionais participantes na pesquisa aponta para fatores responsáveis pelos processos que contribuíram para a reestruturação da economia. Além disto, apresentam as consequências que transformações no mercado de design local representaram para estes profissionais na busca por estratégias que favorecessem a estabilidade de seus empreendimentos em períodos de instabilidade econômica.
\end{abstract}

Palavras-chave: economia criativa. design. Lisboa. 


\title{
Creative entrepreneurship: the guidelines of the fashion design sector in Lisbon from the perspective of creative producers
}

\begin{abstract}
The study presented aims to raise questions about the perception of creative producers and their ability to participate and adapt to the emerging economy model, based on the development of creativity and authoral processes of product creation. To this end, it took into account the transformations observed over the past decade wich presented Lisbon as a city with potential to become an exponente in innovation and creative entrepreneurship. From documentary surveys of recent economic indexes and identification of initiatives, brands and copyright producers, some of the factors that favored the development of the sector were verified. The data that make up the research were based on interviews with entrepreneurial designers, whose speeches provided material for further analysis. The analysis of the perspective of the professionals participating in the research points to factors responsible for the processes that contributed to the restructuring of the economy. In addition, they present the consequences that transformations in the local design market represented for these professionals in the search for strategies that favor the stability of their brands in periods of economic instability.
\end{abstract}

Keywords: creative economy. design. Lisbon. 


\title{
Emprendimiento creativo: las pautas del sector del diseño de moda en Lisboa desde la perspectiva de los productores creativos
}

\begin{abstract}
RESUMEN
El estúdio presentado tiene como objetivo plantear interrogantes sobre la percepción de los produtores creativos y su capacidade de participación y adaptación al modelo de economia emergente, a partir del desarrollo de la creatividad y los processos autorales de creación de produtos. Para ello, tuvo en cuenta las transformaciones observadas durante la última década que presentaran a Lisboa como uns ciudad con potencial para convertirse en un exponente de la innovación $y$ el emprendimiento creativo. A partir de encuestas documentales de índices económicos recientes e identificación de iniciativas, marcas y productores de derechos de autor, se verificaron algunos de los factores que favorecieron el desarrollo del sector. Los datos que componen la investigación se basaron en entrevistas con diseñadores emprendedores, cuyos discursos proporcionaron material para un análisis más profundo. El análisis de la perspectiva de los profesionales que participan en la investigación apunta a factores responsables de los procesos que contribuyeron a la reestructuración de la economía. Además, presentan las consecuencias que las transformaciones en el mercado del diseño local representaron para estos profesionales en la búsqueda de estrategias que favorezcan la estabilidad de sus marcas en períodos de inestabilidad económica.
\end{abstract}

Palabras clave: economía creativa. diseño. Lisboa. 


\section{INTRODUÇÃO}

Nos últimos anos a cidade de Lisboa tem presenciado uma série de mudanças, especialmente em âmbitos como o social e o econômico. Por sua vez, se faz necessário às organizações buscar adaptar-se da melhor forma às dinâmicas de um mercado que apresentou níveis altos de instabilidade no decorrer da última década. Sob tal perspectiva, a busca por alternativas que impactassem nos setores de inovação e na renovação de estratégias se tornou em um dos principais focos dos atores envolvidos na produção e economia locais.

Em observação ao cenário internacional de recessão que instalou-se gradativamente desde 2008 na Europa, Bauman (2008) diz que os momentos de crise são acompanhados por momentos de intensas transformações sociais e culturais, adquirindo inclusive aspectos positivos, como o estímulo a uma (re)adequação dos atores envolvidos. Desse modo, foi proposto então buscar compreender de que forma os produtores locais se adaptaram a este mercado em transformação.

A proposta da presente investigação teve como intuito observar os pontos de vista de designers enquanto produtores criativos, diante das recentes mudanças econômicas e culturais ocorridas na cidade de Lisboa. A visibilidade dada aos criadores portugueses no setor de desenvolvimento de produtos de Design trata-se de uma importante motivação, a fim de que se possa compreender suas percepções e estratégias em detrimento às transformações que se configuraram em escala local e sua própria participação em benefício deste cenário. 


\section{DEFINIÇÃO E CARACTERÍSTICAS DAS INDÚSTRIAS CRIATIVAS}

A ressignificação cultural e industrial na pós-modernidade foi capaz de estabelecer novas relações de produção e consumo de bens materiais e imateriais. O avanço tecnológico e o consequente destaque de questões como sustentabilidade, crise mundial e escassez de recursos fez com que o conceito de Economia Criativa viesse a se tornar "[...] cada vez mais importante no mundo como a principal ligação entre a cultura, a economia e a tecnologia" (NEWBIGIN, 2010, p.9).

Segundo a Conferência das Nações Unidas sobre Comércio e Desenvolvimento (UNCTAD), em um relatório de 2008 é proposta a seguinte definição para o termo:

No mundo contemporâneo, um novo paradigma de desenvolvimento está emergindo. Ele liga a economia e a cultura, abarcando os aspectos econômicos, culturais, tecnológicos e sociais do desenvolvimento, tanto no nível macro como no micro. O centro deste novo paradigma está no fato de que a criatividade, o conhecimento e o acesso à informação estão sendo cada vez mais reconhecidos como poderosos motores que dirigem o crescimento no mundo globalizado (UNCTAD, 2008, p.3).

Por definição, os produtos e serviços desenvolvidos pelas indústrias e mercados que fazem parte da Economia Criativa ultrapassam a noção de economia das artes ou economia da cultura, que por sua vez reconhece atividades estritamente artísticas e culturais. Ela abarca atividades e serviços que dependem da criatividade como geradora de recursos e de inovação. 
Segundo a Conferência das Nações Unidas sobre Comércio e Desenvolvimento (UNCTAD), em um relatório de 2010, as Indústrias Criativas consideram:

Os ciclos de criação, produção e distribuição de bens e de serviços que utilizam criatividade e capital intelectual como recursos primários; que constituem um conjunto de atividades baseadas em conhecimento, focadas, entre outros, nas artes, que potencialmente gerem receitas de vendas e direitos de propriedade intelectual; que constituem produtos tangíveis e serviços intelectuais ou artísticos intangíveis com conteúdo criativo, valor econômico e objetivos de mercado; que se posicionam no cruzamento entre os setores artísticos, de serviços e industriais; e que constituem um novo setor dinâmico no comércio mundial (UNCTAD, 2010, p.8).

Desse modo, ficou definido que a então denominada Economia Criativa englobaria o conjunto das Indústrias Criativas, sendo "aquelas atividades que tem sua origem na criatividade, na habilidade e no talento individual, e que potencializam a criação de emprego e riqueza através da geração e exploração da propriedade intelectual" (NEWBIGIN, 2010, p.15).

Florida (2011) compreende este modelo econômico como responsável por grandes transformações em termos de valores, estilo de vida, hábitos de trabalho e de consumo. Se antes a informação e suas redes de comunicação já demonstravam poder de influência na sociedade, nessa nova comunidade de indivíduos e empresas criativas, a informação, a criatividade e o trabalho imaterial tornam-se insumos indispensáveis para o funcionamento e dinâmica dos mercados que integram as Indústrias Criativas.

A UNCTAD classifica as seguintes áreas como setores criativos (Esquema 1):

Esquema 1: Classificação da UNCTAD para as Indústrias Criativas 


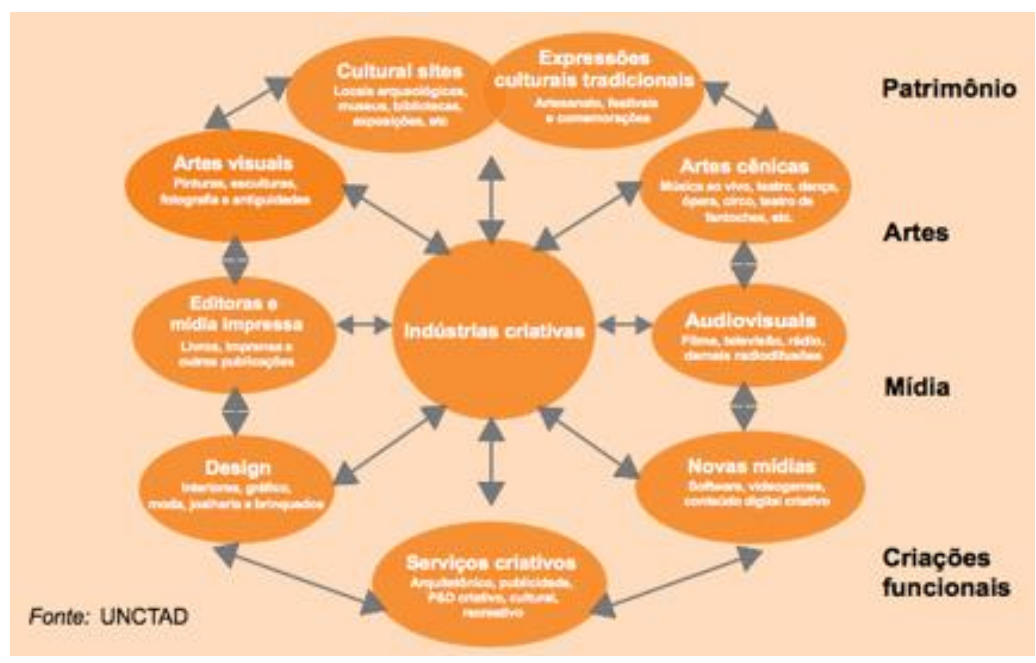

Fonte: UNCTAD (2010)

Segundo John Howkins (2000), a maior parte das empresas deste setor geralmente são de porte pequeno a médio e que, por esta razão, detém um maior potencial para a inovação e são as mais favorecidas pelo crescimento do setor criativo. Outro fator apontado é o do trabalho colaborativo, mencionado por Florida (2011). Empresas que se desenvolvem em meio a um período de trocas tão intensas e velozes, devem estar preparadas para trabalhar colaborativamente com outros profissionais, outras empresas e mesmo com seus clientes/consumidores.

\subsection{O design como indústria criativa}

Dentre os diversos setores englobados pelas definições da Economia Criativa e apresentados no tópico anterior, o campo do Design é, por sua vez, o segmento de interesse intrínseco à presente investigação. Para a Conferência das Nações Unidas sobre Comércio e Desenvolvimento (UNCTAD, 2010, p.156) o Design se encaixa na categoria "criações funcionais" das Indústrias Criativas. 
Ainda de acordo com a classificação da UNCTAD (2010), os produtos classificados como Design incluem a arquitetura, objetos de decoração, joias, brinquedos e artigos de vidro e de moda. Para a moda é dada uma ênfase especial, visto o seu importante potencial comercial e em expansão, destacando uma importante diferenciação entre criações de moda exclusivas e artesanais daquelas produzidas em escala industrial.

Segundo Witheley (1993) é também importante considerar que o Design, como setor criativo, está diretamente relacionado a manifestações de situações sociais, políticas e econômicas de uma sociedade. O profissional da criação em Design não se trata apenas de um criador de valor comercial, mas um criador de valor social, cultural, ambiental, político e simbólico a partir do ambiente em que se encontra inserido (MARGOLIN, 2004).

Dada a sua importância, acredita-se que através do Design determinados valores de uma sociedade podem tornar-se compreensíveis para os seus indivíduos por meio da produção material.

\section{LISBOA COMO CENTRO CRIATIVO}

As Indústrias Criativas trouxeram à tona noções que envolvem novos comportamentos de trabalho e de interações profissionais e de consumo. A principal responsável por essas transformações é a classe criativa, os profissionais que impulsionam o setor, e através de suas atividades estimulam o desenvolvimento econômico local. Esses profissionais, por sua vez, não costumam concentrar-se necessariamente onde estão as ofertas de emprego, eles se reúnem em chamados centros de criatividade, "lugares que ofereçam ambientes criativos e estimulantes, ou seja, por lugares que ofereçam abertura e diversidade, além de oportunidades e 
conveniências, onde possam se expressar e legitimar sua identidade" (FLORIDA, 2011, p.11).

Ainda segundo o autor, quando estes Centros Criativos surgem, não é por razões econômicas tradicionais, e nem sempre mediante incentivos do governo local. Esses centros surgem por que é lá que os indivíduos criativos querem estar. Atentas a esse comportamento, as empresas seguem essas pessoas. Ou ainda, como em muitos dos casos, são essas pessoas quem criam as novas empresas em atividade.

Eleita em 2015 como a capital criativa da Europa, Lisboa tem se tornado ao longo dos últimos anos um marco atrativo para idealizadores e jovens criativos de toda a Europa. Já em 2017 foi criado o Observatório das Cidades Culturais e Criativas', uma ferramenta desenvolvida pelo serviço científico interno da Comissão Europeia e que na ocasião de seu lançamento abrangia 168 cidades em 30 países.

Sobre o campo específico de Design, segundo o Instituto Nacional de Estatísticas, do total de empresas classificadas em Portugal em 2015, 8,6\% - 4.555 empresas - são referentes a atividades de Design e apresentaram um crescimento de $13 \%$ em relação ao ano anterior. Essas empresas, por sua vez, representam $8,2 \%$ do total de empregos gerados nas atividades criativas e $4,7 \%$ de participação no volume de negócios gerados pelo setor criativo no país. Na Área Metropolitana de Lisboa este total é de 1.965 empresas voltadas para atividades de Design e 2.715 profissionais empregados, de acordo com levantamento de 2015.

\section{METODOLOGIA APLICADA}

Para a construção da pesquisa foi adotada uma abordagem indutiva, em que a partir da observação e análise de casos e 
fenômenos isolados é possível propor ou constatar a generalização de um determinado fenômeno (RICHARDSON, 2009; GIL, 2012). Além disso, o estudo pode ser classificado como exploratório e descritivo, visto que pesquisas desta natureza buscam averiguar principalmente quem, como e porque da ocorrência de determinados fenômenos.

Para a seleção da amostra das empresas participantes da pesquisa foram realizadas sondagens iniciais de prospecção por meio de observação participante e assistemática em cinco estabelecimentos colaborativos de criadores locais de Design - We Make, Wetheknot, Real Slow Retail Concept Store, Embaixada e LxFactory -, localizados nos bairros de Alcântara, Príncipe Real e Bairro Alto. Os espaços são localizados em áreas comumente identificadas como redutos de produtores criativos e por também se tratarem de importantes redutos turísticos para a cidade.

Os principais critérios estabelecidos para a escolha da amostra final foi de a) serem empresas de pequeno porte, conforme a classificação da Comissão Europeia (2003) e baseado na definição de Howkins (2000) para os empreendimentos do setor criativo, b) terem os produtos expostos e comercializados em loja/espaço físico, c) serem marcas criadas em sua configuração atual a partir do ano 2010, período estabelecido como marco temporal para a instalação da crise econômica em Portugal e d) deveriam atender, em seu catálogo de produtos, a pelo menos uma das seguintes categorias de projetos de artefatos autorais: vestuário, calçados, joalharia e/ou utilitários/decoração.

Por meio de carta-convite, foi estabelecido o primeiro contato por e-mail com todas as empresas inicialmente cadastradas em um banco de dados digital para controle do diálogo com as mesmas. A medida em que, a partir deste primeiro contato online, as empresas se enquadravam nos 
pré-requisitos estabelecidos para a amostra, foram selecionadas cinco empresas que deveriam compor a amostra final destinada à realização das entrevistas. As entrevistas foram realizadas no ambiente da loja ou ateliê de criação dos entrevistados, a fim de Ihes proporcionar um ambiente confortável e familiar, estimulando assim maiores insights para o diálogo proposto.

O roteiro das entrevistas foi elaborado tendo como principal objetivo investigar com os produtores de Design locais suas percepções sobre o período de crise em Portugal e na capital Lisboa. Além disso, outro ponto relevante para a investigação foram as estratégias utilizadas para a adequação das empresas/marcas à realidade de instabilidade econômica que se instalou no país principalmente entre os anos de 2010 e 2013. Em contrapartida, aspectos como incentivos governamentais e os possíveis impactos e consequências das ações de outros setores também foram pontos importantes a serem considerados pelos entrevistados. Todo o diálogo foi registrado por meio de captação de áudio e também sistematizados por meio de transcrição textual.

Posteriormente, foi realizada uma análise mais detalhada de pontos de vista dos respectivos criadores entrevistados. Como ferramenta de pesquisa fundamentalmente ancorada nos estudos linguísticos e até mesmo na Psicanálise, a Análise do Discurso visa construir bases de entendimento dialógico na interlocução verbal (enunciado) entre dois sujeitos, enunciador e enunciatário (BAKHTIN, 1997).

Na noção de discurso proposta por Orlandi (2001), uma mensagem é compreendida como informação e passada de um emissor a um interlocutor, que por sua vez capta e decodifica a mensagem de forma isolada. A Análise de Discurso possibilita o acesso ao Imaginário (ou Formações Imaginárias) dos sujeitos envolvidos em um determinado 
grupo ou campo de investigação. Essas formações imaginárias, forjadas com o auxílio da linguagem, revelam como esses sujeitos imaginam a si mesmos e as relações sociais que o envolvem. O discurso torna-se objeto simbólico de análise e demanda uma leitura cuidadosa, atenta e disciplinada do leitor.

Os resultados advindos das entrevistas e respectivas observações dos discursos dos profissionais entrevistados podem ser verificadas no tópico a seguir.

\section{APRESENTAÇÃO E ANÁLISE DOS RESULTADOS}

No Quadro 1 a seguir estão especificadas as principais características das empresas de Design participantes, a fim de ilustrar seu enquadramento na pesquisa, aqui indicadas por E1, E2, E3, E4 e E5, conforme a ordem de realização as entrevistas.

Quadro 1: Perfil das empresas investigadas

\begin{tabular}{|c|c|c|c|c|c|}
\hline Empresa & Segmento & $\begin{array}{c}\text { Ano de } \\
\text { criaçăo } \\
\text { da } \\
\text { empresa }\end{array}$ & $\begin{array}{l}\text { Porte da } \\
\text { empresa }\end{array}$ & $\begin{array}{c}\text { Cidade de } \\
\text { origem/atuaçào }\end{array}$ & $\begin{array}{c}\text { Zona de } \\
\text { atuaçắo } \\
\text { em } \\
\text { Lisboa }\end{array}$ \\
\hline E1 & Joalharia & 2010 & Microempresa & Lisboa & $\begin{array}{l}\text { Bairro } \\
\text { Alto }\end{array}$ \\
\hline E2 & $\begin{array}{c}\text { Acessórios } \\
\text { (Bolsas) }\end{array}$ & 2011 & Microempresa & Lisboa & $\begin{array}{c}\text { Bairro } \\
\text { Alto }\end{array}$ \\
\hline E3 & Vestuário & 2016 & Microempresa & Mafra/Lisboa & $\begin{array}{l}\text { Príncipe } \\
\text { Real }\end{array}$ \\
\hline E4 & Joalharia & 2017 & Microempresa & $\begin{array}{l}\text { São João do } \\
\text { Estoril/Lisboa }\end{array}$ & Alcântara \\
\hline E5 & Vestuário & 2016 & Microempresa & Lisboa & $\begin{array}{c}\text { Príncipe } \\
\text { Real }\end{array}$ \\
\hline
\end{tabular}

Fonte: Elaborado pela autora a partir de dados da pesquisa (2018)

As empresas encontram-se divididas em três segmentos voltados para a criação em Design: Joalheria (2 empresas), Acessórios (1 empresa) e Vestuário (2 empresas). Inicialmente, os artefatos de mobiliário também foram 
cogitados como bens de consumo correspondentes aos interesses da pesquisa, porém a oferta deste segmento foi considerada inexpressiva ou inexistente nas áreas delimitadas para a investigação em campo.

Todas as empresas se identificaram como micro empreendimentos. Para esse enquadramento foi utilizada a definiçãoii proposta pela Comissão Europeia para identificar o porte de empresas em Portugal. Desse modo, todas as empresas possuem menos de dez funcionários efetivos envolvidos diretamente na produção da marca.

Por trabalharem com produção em pequena escala, o trabalho das empresas muitas vezes aproxima-se de uma produção artesanal, sendo na maioria dos casos os próprios proprietários quem desenvolvem todo conceito dos projetos, além de participarem tecnicamente, sendo geralmente assistidos por outros poucos profissionais que se encarregam da confecção dos objetos em caráter auxiliar. Apenas no caso da empresa E5 (Vestuário) todos os produtos são confeccionados por profissionais contratados, limitando sua participação nas etapas de planejamento, supervisão e divulgação dos produtos.

Todas as empresas participantes foram criadas entre os anos de 2010 e 2017, mantendo-se desde então em sua configuração atual. Alegadamente, os entrevistados estabeleceram dois pontos principais e aparentemente divergentes como motivadores e influenciadores do surgimento e desenvolvimento das empresas. Os discursos a seguir (Quadro 2) representam esses dois pontos de convergência do diálogo proposto, e serão melhor esclarecidos adiante. 
Quadro 2: Comparativo dos discursos sobre o período de crise em Lisboa/Portugal

\begin{tabular}{|c|c|}
\hline \multicolumn{2}{|r|}{ Período de crise } \\
\hline Empresa & Discurso \\
\hline $\mathrm{E} 1$ & $\begin{array}{r}\text { "Houve muita gente desempregada, entre os } \\
\text { trinta ou quarenta (anos) e toda a gente se pôs a } \\
\text { fazer coisas sozinho. Teve este impacto...gente } \\
\text { com formação. Muita gente a produzir coisas boas } \\
\text { e com qualidade. E mesmo as feiras de rua } \\
\text { ganharam imensa qualidade por causa } \\
\text { disso....Então a crise influenciou de forma positiva. } \\
\text { Foi a minha aposta. }\end{array}$ \\
\hline E2 & $\begin{array}{r}\text { "A empresa passou por poucas dificuldades } \\
\text { durante o período da crise" }\end{array}$ \\
\hline E3 & $\begin{array}{l}\text { "A crise motivou pessoas que, tal como eu, } \\
\text { redirecionaram seu trabalho criativo para o } \\
\text { Design, sozinha ou em parcerias. E penso que } \\
\text { isso afetou de forma positiva a criação local". }\end{array}$ \\
\hline E4 & $\begin{array}{r}\text { "Muitos colegas não arranjavam trabalho em } \\
\text { nada. E mesmo quando eram estágios, eram não } \\
\text { remunerados. Hoje em dia já conseguem estágios } \\
\text { em que se paga decentemente. E foi por isso } \\
\text { mesmo, porque não arranjavam nada que fosse } \\
\text { bom que se viram por optar por seguirem } \\
\text { sozinhos". }\end{array}$ \\
\hline E5 & $\begin{array}{l}\text { "Acho que Lisboa, Portugal em geral passou por } \\
\text { uma grande crise. E em períodos de crise acho } \\
\text { que a criatividade das pessoas aumenta. E eu } \\
\text { acho que é a criatividade a ser desenvolvida por } \\
\text { causa de uma crise. Eu criei uma empresa, nunca } \\
\text { pensei. Trabalhei com moda durante uns anos, } \\
\text { era diretora do Gucci...mas eu já tinha esse sonho } \\
\text { há dez anos. Eu aproveitei, foi uma oportunidade. } \\
\text { Eu pensei "como é que eu vou aproveitar agora } \\
\text { este período e tirar vantagem de um período que } \\
\text { é uma desvantagem?" Portanto, pensei, vou } \\
\text { experimentar e fazer uma coisa que eu gosto" }\end{array}$ \\
\hline
\end{tabular}

Fonte: Elaborado pela autora a partir das entrevistas realizadas (2018)

\section{Análise dos discursos:}

Esta primeira abordagem se trata da influência mais imediata apontada pelos entrevistados como fator influenciador da criação das marcas. Com exceção da empresa E2 (Acessórios), as demais observaram na crise uma oportunidade de empreender no setor criativo de forma autônoma. Muitos profissionais perceberam na criação autoral uma possibilidade de empreenderem e de reingressarem no 
mercado de trabalho, oferecendo propostas de produtos fundamentados na autonomia criativa de seus idealizadores.

O aumento dessas atividades autônomas ajudam a ilustrar a opinião de Bauman (2008), quando este afirma que os momentos de crise são acompanhados por momentos de intensas transformações. Os momentos de instabilidades políticas ou econômicas acabam ganhando desdobramentos positivos quando tratam-se de um importante propulsor de mudanças e adaptações por parte dos envolvidos. Desse modo, a instabilidade financeira em Portugal impulsionou os entrevistados a buscarem na criação e no Design pressupostos estratégicos para permanecerem inseridos no mercado, que nos anos seguintes apresentou índices cada vez mais positivos de recuperação.

Por outro lado, com as consequências resultantes da crise nos demais países da União Europeia, Portugal tornou-se um destino acessível e atraente, o que motivou um aumento do investimento no setor turístico no país. Desse modo, analisando estas transformações, os entrevistados se posicionaram conforme é possível verificar no Quadro 3 a seguir. 
Quadro 3: Comparativo dos discursos sobre o Turismo Internacional em Lisboa/Portugal

\begin{tabular}{|c|c|}
\hline \multicolumn{2}{|r|}{ Turismo internacional } \\
\hline Empresa & Discurso \\
\hline $\mathrm{E} 1$ & $\begin{array}{c}\text { "Hoje em dia Lisboa está entupida de turistas e é } \\
\text { isto que está a fazer os negócios funcionarem. Eu } \\
\text { diria que no princípio havia bastante turismo, mas } \\
\text { não tanto como agora. Depois houve uma quebra } \\
\text { imensa. Há dois anos para cá que sinto muita } \\
\text { diferença no turismo e os portugueses voltaram a } \\
\text { comprar, mas não é a mesma coisa que era antes } \\
\text { da crise, não é comparável". }\end{array}$ \\
\hline E2 & "O público tem sido constante". \\
\hline E3 & $\begin{array}{r}\text { "Lisboa é uma cidade cada vez mais visitada por } \\
\text { cidadãos estrangeiros [...] Meu público é cada vez } \\
\text { mais estrangeiros com uma idade entre } 25 \text { e } 40 \\
\text { anos de idade, habituado a viajar". }\end{array}$ \\
\hline E4 & $\begin{array}{r}\text { "Quando voltei de Londres percebi uma enorme } \\
\text { diferença em relação ao turismo. Acho que a } \\
\text { cidade de Lisboa proporciona visibilidade } \\
\text { internacional aos produtos aqui desenvolvidos". }\end{array}$ \\
\hline E5 & $\begin{array}{l}\text { "Na época em que a empresa foi criada o fluxo do } \\
\text { turismo já tinha aumentado bastante. Portugal } \\
\text { está no mapa da Europa como um dos destinos } \\
\text { favoritos dos europeus, por facilitar os impostos. } \\
\text { É um país bastante atrativo em vários aspectos. } \\
\text { Acho que Portugal está a sair da crise, já há mais } \\
\text { poder de compra. As pessoas já estão querendo } \\
\text { comprar mais. E depois tem o complemento dos } \\
\text { turistas, em que há muito investimento em } \\
\text { Portugal, tanto no imobiliário como no comércio. } \\
\text { O turismo está diretamente relacionado ao } \\
\text { impulsionamento dessa economia". }\end{array}$ \\
\hline
\end{tabular}

Fonte: Elaborado pela autora a partir das entrevistas realizadas (2018)

\section{Análise dos discursos:}

O crescimento acelerado do setor turístico e suas relações com o aumento da produção criativa em Lisboa apresentou novos questionamentos sobre a influência e importância do desenvolvimento local para as atividades dos entrevistados. Tendo se convertido em atraente foco turístico, esta foi uma realidade que também trouxe consequências, na opinião dos entrevistados. Quanto ao seu posicionamento no mercado, todas as empresas apontaram a cidade de Lisboa como seu principal centro de circulação de produtos. No decorrer das 
entrevistas, os participantes esclarecem mais detalhadamente a relação entre as marcas e a importância representada pela cidade para o desenvolvimento e posicionamento das mesmas no mercado (Quadro 4):

Quadro 4: Comparativo dos discursos sobre a adequação da empresa no mercado de Design em Lisboa

\begin{tabular}{|r|r|}
\hline \multicolumn{2}{|c|}{ Posicionamento no mercado local } \\
\hline Empresa & Discurso \\
\hline E1 & $\begin{array}{r}\text { "A cidade acaba atraindo turistas, que } \\
\text { consequentemente..." }\end{array}$ \\
\hline E3 & $\begin{array}{r}\text { "Há algumas estruturas recentemente criadas que } \\
\text { impulsionam a criação de negócios em várias } \\
\text { áreas, incluindo o Design, como o Centro de } \\
\text { Inovação da Mourariaiii, onde agora estamos } \\
\text { enquadrados". }\end{array}$ \\
\hline E4 & $\begin{array}{r}\text { "É uma cidade cada vez mais cosmopolita". } \\
\text { turismo, percebe-se a possibilidade de chegar a } \\
\text { mais gente mais facilmente. E também pela } \\
\text { exposição que é muito mais fácil, no centro de } \\
\text { Lisboa". }\end{array}$ \\
& $\begin{array}{r}\text { "Eu acho que Portugal hoje em dia representa um } \\
\text { bocadinho do que São Francisco representou há } \\
\text { alguns anos. Eu já estou em algumas lojas de } \\
\text { Lisboa, mas Lisboa não influencia muito em minha } \\
\text { marca. Eu acho que o público em geral está muito } \\
\text { cansado das marcas em geral, como uma Zara, } \\
\text { uma H\&M e etc, porque são produtos, não tem } \\
\text { alma. E eu acho que todas as marcas precisam ter } \\
\text { uma alma". }\end{array}$ \\
\hline
\end{tabular}

Fonte: Elaborado pela autora a partir das entrevistas realizadas (2018)

\section{Análise dos discursos:}

Os entrevistados são unânimes em considerar Lisboa o ponto central de suas atividades, principalmente no que diz respeito ao alcance dos consumidores e comunicação da marca, em espaços físicos e de ampla circulação turística. O turismo é apontado, mais uma vez, como fator determinante para a visibilidade das marcas. Em contrapartida, também é mencionada a recuperação e revitalização de espaços públicos, a fim de impulsionar a circulação e investimento turístico nessas vias. Nos últimos anos, diferentes espaços 
públicos foram revalorizados como emergentes centros de inovação, criatividade, gastronomia e interesse turístico, como o Mercado da Ribeira, o bairro de Marvila e a própria Mouraria, contando com o apoio e organização dos setores de administração pública local.

A atração de um perfil de público diversificado, contribui para a transformação de Lisboa em um centro cosmopolita, social e culturalmente estimulante, um dos principais pontos abordados nas definições de Florida (2011) sobre a estruturação de Centros Criativos. Por outro lado, o autor também afirma que nem sempre esses centros estão diretamente ligados a incentivos governamentais e mais por iniciativas próprias dos profissionais criativos. Questionados sobre a participação de iniciativas governamentais em apoio direto às suas atividades ou às atividades do setor criativo em Lisboa, os entrevistados apresentaram diferentes perspectivas e do impacto em seu trabalho, como pode ser visto a seguir. 
Quadro 5: Comparativo dos discursos sobre apoio governamental aos empreendedores

\begin{tabular}{|c|c|}
\hline \multicolumn{2}{|r|}{ Políticas de apoio governamental } \\
\hline Empresa & Discurso \\
\hline $\mathrm{E} 1$ & $\begin{array}{r}\text { "Nesta área eu acho que não existe. Em joalheria } \\
\text { não existe muito, a não ser para grandes } \\
\text { empresas, que no caso não são estes pequenos } \\
\text { criadores". }\end{array}$ \\
\hline E2 & $\begin{array}{r}\text { "Pontualmente existem sim, mas não existe } \\
\text { grande critério de qualidade nas investidas do } \\
\text { Estado. O Design está erradamente associado a } \\
\text { status e passa, infelizmente, muito pela } \\
\text { celebração de nomes estabelecidos no meio } \\
\text { alimentando o star system que se criou em torno } \\
\text { desta disciplina". }\end{array}$ \\
\hline E3 & $\begin{array}{r}\text { "Penso que algo está a mudar, mas não me parece } \\
\text { que seja uma questão política por parte das } \\
\text { entidades governativas" }\end{array}$ \\
\hline E4 & $\begin{array}{r}\text { "É mais por iniciativa própria. Agora é que a } \\
\text { Câmara de Lisboa abriu ateliês no centro de } \\
\text { Lisboa, mas são todos a pagar e contratos de até } \\
\text { quatro anos. Mas não me cheguei a informar } \\
\text { porque andava com outro projeto nosso, então } \\
\text { esse projeto não dava. Mas em geral, não há } \\
\text { grandes incentivos". }\end{array}$ \\
\hline E5 & $\begin{array}{r}\text { "A um nível mais microeconômico existem } \\
\text { mercados e feiras que o que precisa mais é } \\
\text { divulgar e começarem a ter uma melhor } \\
\text { visibilidade. São conceitos novos que estão a } \\
\text { ajudar muito e o mercado está a borbulhar a nível } \\
\text { de microempresas, marcas, juntamente com as } \\
\text { redes sociais". }\end{array}$ \\
\hline
\end{tabular}

Fonte: Elaborado pela autora a partir das entrevistas realizadas (2018)

\section{Análise dos discursos:}

Conclui-se que há dois posicionamentos quanto ao incentivo governamental. De um lado há empreendimentos suficientemente estruturados a ponto de não terem sido massivamente afetados pela crise econômica - caso da empresa do entrevistado E2 (Acessórios) -, que além disso encontra apoio nas iniciativas públicas de desenvolvimento locais. Por outro lado, há os criadores que precisaram buscar por oportunidades mediante a participação em feiras e mercados criativos espalhados em pontos estratégicos da cidade, nomeadamente os bairros de Alcântara e Príncipe Real (mercados criativos e feiras). Também no bairro do Príncipe 
Real, bem como no Bairro Alto, regiões centrais da cidade, multiplicam-se as lojas colaborativas, cujo modelo de atividade será comentado a seguir.

A importância do trabalho colaborativo apontado por Florida (2011) é fortemente identificado neste momento da entrevista por todos os entrevistados. Sobre a opção de se reunirem em espaços colaborativos, os entrevistados relataram o que se encontra descrito a seguir no Quadro 6.

Quadro 6: Comparativo dos discursos sobre o trabalho em espaços colaborativos

\begin{tabular}{|c|c|}
\hline \multicolumn{2}{|r|}{ Espaços colaborativos } \\
\hline Empresa & $\begin{array}{ll} & 0 \\
& 0\end{array}$ \\
\hline $\mathrm{E} 1$ & $\begin{array}{l}\text { "Isso começou por causa de uma feira que nós começamos a fazer há } \\
\text { muitos anos. Eu fui a última a entrar, mas os outros dois (uma marca de } \\
\text { vestuário e a outra de calçados) casavam muito bem. E depois vieram } \\
\text { falar comigo porque acharam que seria mais um produto que, no bom } \\
\text { sentido, não ocuparia muito espaço físico e faz um conjunto muito } \\
\text { simpático (com as outras peças)" }\end{array}$ \\
\hline E2 & $\begin{array}{l}\text { "Atualmente é a única forma de podermos ter um espaço aberto ao } \\
\text { público, já que o preço imobiliário estrangularia qualquer negócio } \\
\text { pequeno que se dedicasse à produção de artigos próprios. A vantagem } \\
\text { principal é a divisão de custos (renda, contas, funcionários) e } \\
\text { responsabilidades. A principal desvantagem é a descaracterização ou } \\
\text { diluição das identidades dos projetos em prol de um conceito comum" }\end{array}$ \\
\hline E3 & $\begin{array}{r}\text { "Eu gosto do contato com o público em ambientes de feiras. A } \\
\text { oportunidade surgiu depois de uma proposta apresentada por mim à } \\
\text { organização do evento" }\end{array}$ \\
\hline E4 & $\begin{array}{l}\text { "Na loja a oportunidade surgiu por amigos em comum e uma das } \\
\text { administradoras do espaço estava lá. E mostrando os trabalhos houve } \\
\text { um interesse e começamos a falar da possibilidade de pôr lá coisas" }\end{array}$ \\
\hline E5 & $\begin{array}{l}\text { "Foi um acaso. Eu por acaso queria estar presente no Príncipe Real e } \\
\text { gostei daquela loja. Eu gosto de estar em lojas que tenham um objetivo } \\
\text { parecido com o meu. E o Príncipe Real é uma zona muito trendy". }\end{array}$ \\
\hline
\end{tabular}

Fonte: Elaborado pela autora a partir das entrevistas realizadas (2018)

\section{Análise dos discursos:}

Novamente, dois são os pontos que divergem no diálogo e que apontam as vantagens e desvantagens do trabalho colaborativo no formato apresentado nesses espaços compartilhados. As principais vantagens são a possibilidade de apresentar os produtos em um espaço físico, estabelecendo um acesso direto ao fluxo de turistas que circulam nas áreas delimitadas para a pesquisa. A questão 
imobiliária foi um dos fatores mais mencionados como reflexo da crise, e posteriormente, também de uma possível sobrecarga desse mesmo fluxo de estrangeiros em Lisboa, que ocasionou um superfaturamento de valores imobiliários na cidade. Empreendedores compreenderam como vantajoso para todos os envolvidos o compartilhamento dos lojas físicas, principalmente quando também há uma partilha consolidada de valores entre as marcas que integram o espaço.

Além disso, a importância da identidade cultural local como atrativo e diferenciador para o público turístico, também viabiliza o viés da divulgação dos criadores nesse formato. Não foi incomum, por exemplo, encontrar espaços que ressaltassem em vitrines, lojas online e redes sociais expressões como "Made in Lisbon", "Made in Portugal" ou "Made by portuguese designers ${ }^{i v " ~ c o m o ~ f o r m a ~ d e ~ v a l o r i z a r ~ o ~}$ expertise dos profissionais e as tradições locais.

Figura 2: Vitrines de lojas colaborativas em Lisboa localizadas no Bairro Alto
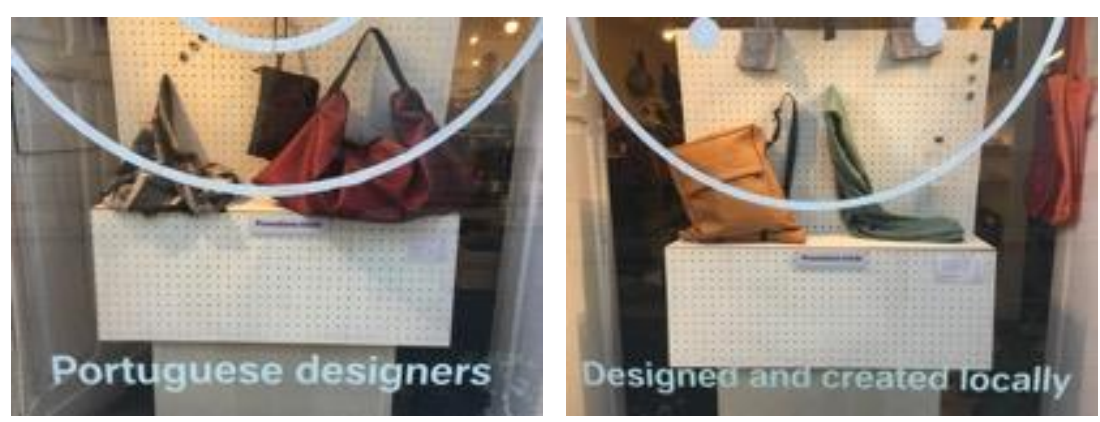

Fonte: Registro da autora (2018)

Quando questionados sobre a importância da label "Made in Portugal" e quanto à estratégia de adotá-la em seu processo de posicionamento de mercado, os profissionais entrevistados se posicionaram conforme apresentado no Quadro 7 a seguir: 
Quadro 7: Comparativos dos discursos sobre o fator "Made in Lisboa/Portugal"

\begin{tabular}{|c|c|}
\hline \multicolumn{2}{|r|}{ O fator "Made in Lisbon/Portugal" } \\
\hline Empresa & Discurso \\
\hline $\mathrm{E} 1$ & $\begin{array}{r}\text { "Sim, sim, eu acho que (o uso da label) valoriza muito. Nós não temos } \\
\text { aqui na vitrine da loja, mas vamos mudar por um acaso e vamos pôr, } \\
\text { porque foi uma coisa que achamos que calhou mesmo" }\end{array}$ \\
\hline E2 & $\begin{array}{r}\text { "Em parte sim. A produção nacional tem um bom standard de qualidade } \\
\text { e a nomeação do local de produção produz valor" }\end{array}$ \\
\hline E3 & $\begin{array}{l}\text { "Talvez não com o impacto tão rápido como se desejaria, mas aos } \\
\text { poucos parece que o "made in Portugal" traz mais confiança ao } \\
\text { consumidor" }\end{array}$ \\
\hline E4 & $\begin{array}{r}\text { "Eu acho que é capaz de ser para algumas pessoas. Portugal está agora } \\
\text { a crescer em termos de joalharia contemporânea. Eu penso que para } \\
\text { algumas pessoas estrangeiras há de ter bastante peso ter sido um } \\
\text { produto feito cá". }\end{array}$ \\
\hline E5 & $\begin{array}{l}\text { "Atrai. É um selo com muito peso. Portugal está muito na moda. Então } \\
\text { tudo que é "made in Portugal", "Made in Lisbon" está na moda". }\end{array}$ \\
\hline
\end{tabular}

\section{Análise dos discursos:}

Tradicionalmente reconhecida por particularidades artesanais, gastronômicas e culturais, o trabalho desenvolvido localmente detém a credibilidade do know-how local. Como centro criativo, é suposto pelos entrevistados que a cidade ofereça a configuração ideal para que possam justamente expressar-se e legitimar suas identidades.

A legitimação desse comportamento como possibilidade estratégica se apresenta no crescimento de mercado identificado pelas estatísticas, tanto relacionado ao crescimento do número de produtores como das transformações já discutidas do público que consome. O retorno a uma nova estabilidade econômica, possibilita uma retomada da credibilidade e da confiança nesse modelo de mercado que se consolida e que detém esse reconhecimento. Ou como relata um dos entrevistados, "Portugal está muito na moda".

\section{CONSIDERAÇÕES FINAIS}


O estudo apresentado teve como intuito investigar mudanças verificadas no mercado criativo da cidade de Lisboa, tendo em vista discursos de profissionais de criação em Design. A utilização de entrevistas e posterior análise dos discursos dos profissionais entrevistados permitiu verificar alguns dos impactos e consequências que resultaram do período de recessão econômica e quais estratégias foram possíveis, a fim de reposicionar as atividades voltadas para o Design nesse contexto econômico.

Os investimentos direcionados para o turismo e a consequente resposta positiva do setor, ocasionou um fluxo de consumidores estrangeiros que, por sua vez, favoreceu uma renovação na economia. O Design português apresentou alternativas de produtos acessíveis e inovadores para este público que, por sua vez, levou a qualidade do "Made in Portugal" a conhecimento do mercado internacional. Ter uma forte consciência de identidade local foi um fator apontado como vantajoso para os empreendimentos do setor criativo. Em um cenário econômico que por décadas veio incentivando a globalização e a massificação da produção industrial, se diferenciar a partir da identidade e da diversidade cultural em uma região se torna um diferencial estratégico (FLORIDA, 2011, p.228-230).

Trabalhar no formato colaborativo, ainda que amplamente praticado, por vezes não é considerada a forma ideal de apresentar os produtos, pois consideram que apresentar muitos produtos em um mesmo local físico possa projudicar a força da marca. Porém, na opinião dos criadores, torna-se a opção mais viável, uma vez que, para os pequenos produtores os valores dos imóveis se tornaram impraticáveis na região central de Lisboa, principal foco do turismo local. Uma saída é o empenho por uma remodelação da cidade, levando especialmente em consideração o fator imobiliário e de 
incentivo aos novos negócios que estão em desenvolvimento e buscando se integrarem ao mercado. Desse modo, se evitará que apenas grandes cadeias de empresas tenham espaço nos principais pontos da cidade e beneficiará a multiplicidade e diversidade dos pequenos negócios, que ainda buscam por incentivos para se desenvolverem e se consolidarem.

\footnotetext{
' Ver site da Comissão Europeia. The Cultural and Creative Cities Monitor. Disponível em https://compositeindicators.jrc.ec.europa.eu/cultural-creative-cities-monitor/ Acesso em 05/05/2018.

ii A recomendação adotada desde 2003 pela Comissão Europeia define Microempresas como aquelas que possuam número de funcionários efetivos inferior a 10 empregados e que possua um volume de negócios inferior ou igual a 2 milhões de euros.

iii O Centro de Inovação da Mouraria trata-se de um importante centro de incubação de projetos e negócios do setor criativo gerenciado pela Câmara Municipal de Lisboa desde 2015. Além de soluções de financiamento e apoio aos incubados, o projeto também visa oferecer apoio à formação, visibilidade e oferta dos serviços e produtos ali desenvolvidos.

iv Traduzido do inglês. "Feito em Lisboa", "Feito em Portugal" ou "Feito por designers portugueses".
}

\section{REFERÊNCIAS}

BAKHTIN, M. Marxismo e Filosofia da linguagem. $8^{a}$ ed. São Paulo: Hucitec, 1997.

BAUMAN, Z. Vida para o consumo: a transformação das pessoas em mercadoria. Rio de Janeiro: Zahar, 2008.

FLORIDA. R. A ascensão da classe criativa. Porto Alegre: L\&PM, 2011.

GIL, A. C. Métodos e técnicas de pesquisa social. São Paulo: Atlas, 2012.

HOWKINS, J. The Creative Economy: how people make money from ideas. London: Penguin Books, 2001.

MARGOLIN, V.; MARGOLIN, S. Um modelo social de design: questões de prática e pesquisa. Revista Design em Foco, v. 1, p. 43-48, 2004. 
NEWBIGIN, J. A economia criativa: um guia introdutório. Londres: British Council, 2010.

ORLANDI, E. P. Análise de Discurso: princípios e procedimentos. Campinas, SP: Pontes, 3a edição, 2001.

RICHARDSON, R. J. Pesquisa Social: métodos e técnicas. 3. ed. São Paulo: Atlas, 2009.

WHITELEY, N. Design for society. Londres: Reaktion Books, 1993.

\section{Documentos eletrônicos}

Associação Industrial do Distrito de Aveiro. Recomendação Europeia de Definição de Pequenas e Médias Empresas. Disponível em http://aida.pt/cms/media/pdf/definicao_europeia_pme.pdf Acesso em 09/06/2018

Câmara Municipal de Lisboa. Iniciativas voltadas para Economia Criativa. Disponível em http://www.cmlisboa.pt/investir/setores-estrategicos/economia-criativa Acesso em 08/05/2018.

Centro de Inovação da Mouraria. Disponível em http://www.cm-lisboa.pt/centro-de-inovacaoda-mouraria-mouraria-creative-hub Acesso em 22/06/2018.

Comissão Europeia. Cultural and Creative Cities Monitor. Disponível em https://compositeindicators.jrc.ec.europa.eu/cultural-creative-cities-monitor/ Acesso em 03/05/2018.

Instituto Nacional de Estatísticas. Estatísticas de Cultura 2016. Disponível em www.gepac.gov.pt/estatisticas-eestudos/estatisticas.aspx Acesso em 08/05/2018.

Organização das Nações Unidas. Conferência das Nações Unidas sobre Comércio e Desenvolvimento. The Creative Economy Report. Disponível em http://unctad.org/pt/docs/ditctab20103_pt.pdf 2010. Acesso em 19/02/2018. 